\title{
HISTÓRIA, LITERATURA E MERCADO LITERÁRIO NA BAHIA OITOCENTISTA: O PROJETO DE ANNA RIBEIRO GÓES BITTENCOURT (1843-1930)
}

\section{Marcelo Souza Oliveira ${ }^{1}$}

Resumo: A Bahia nos fins do século XIX enfrentou várias transformações sociais e econômicas que provocaram o declínio da elite agrária do Recôncavo, composta por senhores de engenho. Nesse período Anna Ribeiro, uma senhora de engenho, pertencente a uma das famílias mais tradicionais e poderosas da Bahia, ousou a colocar em execução um projeto literário com fins de combater as "novidades vindas fora" e, não apenas isso, também de reafirmar a identidade da elite à qual pertencia. Para isso, Anna Ribeiro soube se utilizar do mercado editorial baiano de então, além de transitar de maneira hábil no seio do cânon literário dominante. Esse artigo se propõe a fazer uma análise da atuação dessa escritora dentro desse contexto. Para isso são analisados prólogos, prefácios e dedicatórias de seus romances, além de manuscritos e críticas de literatos da época, pontuando sua atuação em vários periódicos do período.

Palavras-chave: História, Literatura, Mercado literário.

Abstract: Bahia at the end of the XIX century faced several forms of social and economic transformation that caused the decline of the agrarian elite of the Bay, composed of plantation owners. In this period Anna Ribeiro, a lady belonging to one of the most traditional and powerful families of Bahia, dared put into execution a literary project aiming not only to combat 'innovations' but also to reaffirm the identity of the elite to which she belonged. For this, Anna Ribeiro made use of the publishing market of Bahia at the time, operating skilfully within the dominant literary canon. This article aims to analyse the writer's performance within this context. Prologues, forwards and dedications of her novels are analysed, also manuscripts and criticism of literary figures of the time, which marked her performance in several newspapers of the period.

Key words: History, Literature, Literary market.

O cânone literário sempre se manteve alheio à produção que não se enquadrasse nos projetos hegemônicos impostos pela cultura dominante. Eurídice Figueredo (2005) reitera que, no Brasil, um projeto de nação fomentado ainda no século XIX, instituiu um cânon que se sobrepôs às várias expressões das literaturas regionais e locais, além de tentar excluir os autores que não se enquadrassem dentro dos padrões estabelecidos. Um cânon que surgiu em função da ideologia dominante,

1 Graduado em História, Mestrando em Programa de Pós-Graduação em Estudo de Linguagens, na Universidade do Estado da Bahia - UNEB. Endereço eletrônico: professormarcelo @yahoo.com.br. 
para garantir um projeto de nação nos moldes europeus, centrado, em sua maior parte, nos estados brasileiros do centro-sul e voltado para os seus interesses.

Para Nancy Vieira Fontes (1999), a Bahia do século XIX, não entrou no projeto de nação brasileira, principalmente no início da República. O cânon literário brasileiro que passou para a história pertencia ao eixo localizado no centro-sul do país, deixando para trás inúmeros autores também brasileiros das diversas regiões e localidades. Na Bahia, o grupo a que pertencia Afrânio Peixoto, Almanachio Diniz, Fabio Lopes e Xavier Marques se detiveram a escrever uma prosa regionalista de influencia realista ou, por vezes, a assumirem o estilo romântico que predominou no decorrer dos oitocentos, que detinha grande difusão dentro do estado, mas, que por se diferenciar dos padrões do centro hegemônico foi jogado ao ostracismo literário.

Também nesse período, buscando o seu espaço, algumas mulheres transpuseram essas barreiras, lançando-se no mundo das letras, arriscando-se a publicar textos romanescos e poéticos. Esse grupo se atreveu a entrar no mercado literário de então, ousando-se, também, tentar constituir um público alvo e uma literatura distinta das demais produzidas na região, embora também influenciada pela literatura européia. Foi o caso de Amélia Rodrigues, Adelaide de Castro Alves e Anna Ribeiro $^{2}$. Essa ultima foi considerada pela crítica como a primeira romancista baiana, produzindo e publicando uma vasta obra. Sua atuação no cenário literário baiano no final do Oitocentos é o objetivo deste artigo.

Anna Ribeiro de Araújo Góes nasceu em 1843, na vila baiana de Itapicuru, mudando-se com os pais para a freguesia de Sant'anna do Catu no Recôncavo baiano ainda menina. Pertencente a uma das mais conceituadas e antigas famílias da província baiana, que era considerada nas palavras da própria Anna Ribeiro como "uma espécie de aristocracia formada pela classe muito considerada dos senhores de engenho, que era segunda nobreza do país, como era na França a magistratura" (BITTENCOURT, 1992, p. 1).

A realidade de Anna Ribeiro foi bem típica de uma sociedade patriarcal e agrária: escravos, engenhos, barões (era sobrinha e prima de três dos mais poderosos e abastados da região), igreja... Esposa do médico e senhor de engenho Sócrates Bittencourt, primeiro Intendente de Santana do Catu, dedicada esposa empenhou-se em cuidar de seus três filhos, de seu pai e dos serviços domésticos, supervisionando os escravos. Anna Ribeiro pode ser considerada uma típica representante da elite feminina do recôncavo baiano no século XIX. Escritora hábil e detalhista se dedicava a produzir textos para as jovens "sinhazinhas" de seu tempo.

2 A esse respeito ver, ALVES, Marieta. Intelectuais e escritores baianos: breves biografias. Salvador: Prefeitura Municipal do Salvador: Fundação do Museu da cidade, 1997. 
A romancista do Catu foi a primeira romancista baiana, num período em que o cânone literário baiano e brasileiro era dominado por homens. Essa escritora se propôs a produzir textos literários com o intuito de orientar suas conterrâneas nos caminhos da "moral" e dos "bons costumes". Escreveu artigos para vários periódicos da época destacando-se o Almanaque de lembranças luso-brasileiro e a Paladina do lar. A obra de Anna Ribeiro é vasta e diversificada. Nancy Rita Vieira Fontes classifica sua produção literária da seguinte forma: romances sagrados - A filha de Jephté (1882) e Abigail (1921) - e romances profanos - $O$ anjo do perdão (1885), Helena (1901), Lúcia (1903), Letícia (1908) e Suzana (Inédito)Ribeiro também produziu um livro de memórias intitulado Longos serões do campo (1992). Produziu ainda aproximadamente seis contos, dezessete poemas, três hinos religiosos e dezessete artigos. Além de quatro manuscritos na área da crítica literária.

Vários literatos citaram a importância de Anna Ribeiro para a literatura, como é o caso de Almanachio de Diniz, Augusto Machado, Thales de Azevedo, Carlos Eduardo da Rocha, em ocasião do cinqüentenário da morte da escritora. Alguns pesquisadores se detiveram à análise da produção literária feminina no Brasil oitocentista, citando D. Anna como exemplo. Nos anais da Academia de Letras da Bahia estão registrados alguns discursos onde esses e outros imortais não pouparam deferências a Anna Ribeiro e destacando sua importância no cenário da prosa baiana do final do Oitocentos e início do Novecentos, além de destacar a sua atuação na produção voltada para a defesa da moral e na luta contra as "inovações". No entanto, a pesquisa mais completa sobre a autora foi realizada por Nancy Rita Vieira Fontes em sua dissertação de mestrado $A$ bela esquecida das letras baianas: a obra de Anna Ribeiro, na qual a pesquisadora faz o levantamento e classificação da produção literária da obra da autora. Para Fontes, os romances de Anna Ribeiro têm um valor pedagógico, pois as histórias têm a função de mostrar às jovens a necessidade de conservar os "valores e os bons costumes" através de lições de moral explicitamente evocadas em seus escritos. Entretanto, uma análise mais detalhada desses textos revela que mais do que um projeto literário de fins meramente educativos, a literatura de Anna Ribeiro buscava uma afirmação identitária frente às mudanças sociais e econômicas que a Bahia estava passando nos fins do século XIX.

A província baiana nesse momento passou por um processo social e político que permeou uma mudança de comportamento na elite feminina sendo que a literatura para moças teve um papel preponderante nessa questão. Segundo Gilberto Freire, a segunda metade do século XIX é marcada pela decadência do patriarcado rural $^{3}$ que se consolidara nas casas grandes e fazendas ${ }^{4}$. A crise econômica das

3 O conceito aqui expresso se remete à estrutura familiar centrada onde o senhor de engenho reside permanentemente em suas terras, cercado pela mulher, filhos, grupo frequentemente 
atividades agro-exportadoras, sobretudo a canavieira, levou vários membros da elite a instruir-se nas faculdades das capitais, freqüentado, por exemplo, cursos como a medicina e o direito. As idas a capital se tornaram cada vez mais freqüentes estabelecendo contatos crescentes com os ambientes urbanos. As transformações políticas e sociais desse período foram marcadas por acontecimentos como a Abolição da Escravatura e a Proclamação da República. Tal processo foi acompanhado pelo desejo das elites baianas de aderirem ao projeto de "civilidade" européia para a fomentação do projeto de nação brasileira ao passo em que perdiam força no cenário nacional e mesmo regional.

Além das dificuldades no cenário econômico e social, a sociedade baiana dos fins do século XIX, teve que lidar com as idéias e doutrinas vindas da Europa e dos EUA. Doutrinas como o liberalismo, o positivismo, o protestantismo, o espiritismo e outras tantas começaram a ser difundidas nos meios de comunicação baianos, o que gerou protestos da elite baiana, sobretudo da elite feminina, a quem a igreja atribuía o papel de baluarte da "moral e dos bons costumes", restituindo o mês de Maria e o culto mariano com o intuito de formalizar às mulheres as funções de protetoras do lar, da família e da sociedade ${ }^{5}$. Católica fervorosa, Anna Ribeiro inscreveu os valores marianistas em várias de suas personagens, a exemplo da jovem Letícia, protagonista do romance de mesmo nome publicado em Salvador em 1908. Letícia é um exemplo de um estilo de vida, no qual mulher é inscrita como guardiã do lar e da sociedade. Admirada por todos Letícia é caracterizada como uma mulher de caráter irretocável e de uma santidade divinal que lembra em muito a própria Virgem Maria. Ela é encarregada de socorrer o pai - o senhor de engenho senhor Travassos - no leito de morte, mesmo com a incompreensão do marido e também de cuidar dele quando adoece e é abandonado pela amante por quem abandonou a nobre esposa. Tratando-o com todo o respeito que se deve a um marido Letícia sempre recebe em sua casa mesmo sabendo que ele vive uma "paixão infame" com a devassa atriz Edelvira. No final da trama, Eurico se arrepende e volta ao seio do lar implorando o perdão da esposa, ao afirmar: “- Letícia, tens razão em não me acreditar, conheço a profundeza do abismo onde cai e do qual tua mão redentora me tirou" (BITENCOURT, 1908, p. 204). A jovem resiste por algum tempo, mas no final, acaba perdoando seu esposo. A própria narradora se

ampliado pela presença não só de parentes, mais ou menos, próximos - pai, mãe, irmãos, primos - como de afilhados e até de filhos bastardos, além de agregados e escravos (cf. MATTOSO, Kátia M. de Queirós. Babia século XIX: uma província no império. 2. ed. Nova Fronteira. Rio de Janeiro, 1992, p. 188-192, p. 592).

4 A esse respeito ver FREIRE, Gilberto. Sobrados e mucambos: decadência do patriarcado e desenvolvimento do urbano. 15. ed. ver. São Paulo: Global, 2004.

5 A esse respeito ver REIS, Adriana Dantas. Cora: Lições de comportamento feminino na Babia do século XIX. Salvador: Centro de Estudos Baianos da UFBA, 2000. 
encarrega de anunciar o desfecho, no qual "Mancebo, louco de jubilo lançou-se aos pés da esposa beijando-lhe as mãos, não com amor, mas com a adoração que o verdadeiro crente consagra a uma divindade" (Idem, p. 206).

Roger Chartier (1994) afirma que um livro procura instaurar uma ordem, mesmo que caiba ao leitor atribuir-lhe significados. A intenção de convencer suas jovens leitoras desse papel levou Anna Ribeiro à "missão" de educá-las através da literatura. No prólogo de Letícia os termos utilizados por ela ao referir-se aos objetivos do livro são bem alusivos: "Neste romance procuro demonstrar...", "finalmente procuro provar...". Em sua missão Anna Ribeiro propõe a instituição de modelos expressos em suas histórias que levassem às moças um referencial de comportamento. Dentro das mudanças que a elite rural baiana enfrentava no final do século XIX, ela irá representar o papel da mulher para a manutenção de determinados padrões mínimos dentro desse contexto. Tendo contraditoriamente que sair do âmbito privado ao público para a militância em defesa das mulheres e homens de "bem".

O momento de instabilidade identitária vivida pela elite levou a classe dominante a se utilizar de todos os instrumentos possíveis para defender a sua posição na hierarquia social. Michael Pollak (1992) afirma que a construção da identidade é um fenômeno que se produz em referência aos outros, em referência aos critérios de aceitabilidade, de admissibilidade, de credibilidade, e que se faz por meio de negociação direta com os outros. $\mathrm{Na}$ busca pela defesa da moral e dos bons costumes Anna Ribeiro põe em prática um projeto literário que tem por objetivos não só orientar as moças pertencentes ao seu grupo social, mas reafirmar a identidade desse grupo que durante todo o século XIX se manteve na hegemonia no cenário baiano impondo uma ideologia paternalista que reafirmava uma posição de destaque perante da classe senhorial do Recôncavo na sociedade baiana. Os artigos publicados nas revistas femininas da capital nas décadas de 1910 e 1920, têm como objetivo principal combater as idéias vindas de outros países que estavam começando a ser difundidas em solo baiano. Em um artigo intitulado $A$ propaganda do protestantismo, a autora critica as seitas protestantes e atribui o seu crescimento à falta de assistência que os pais - principalmente as mães - estavam dando aos filhos na sua educação.

O projeto literário de Anna Ribeiro, ao contrário do que possa pensar, foi muito bem articulado e executado, sempre de acordo as regras do mercado editorial vigentes na Bahia no último quartel do século XIX, acompanhando as tendências editoriais durante toda a trajetória literária da autora que durou até meados da década de 1920. O seu primeiro romance - $O$ anjo do pedrão (1882) - foi prefaciado pelo Visconde de Taunay, a pedido do primo da autora, o barão de Araújo Góis, fato que evidencia a necessidade de um "padrinho" literário para validar a produção de uma mulher nessa época. Interessante observar que em nota ao barão de A Cor das Letras - UEFS, n. 8, 2007 
Araújo Góes, Taunay declara "ser o primeiro romance de Anna Ribeiro muito complexo para o seu público alvo", ou seja, as mulheres e sugere que "ela escreva sobre temas mais fáceis que fale ao coração do povo". As palavras de Taunay parecem ser um conselho para que a nova autora explorasse o regionalismo como estratégia de identificação com o leitor, conseguindo assim se manter na carreira literária. O autor de Inocência estava também fornecendo um meio de inserção da nova escritora no cenário literário. Ciente de como executar seu projeto, ela tanto se utilizou dessa como de outras estratégias de aceitação. Algumas hoje pouco compreendidas, por obedecerem à outra lógica de vida e de atuação social.

Roger Chartier (2001) assevera que cada livro tem uma vontade de divulgação, dirige-se a um mercado, a um público. Ele deve circular e deve ganhar extensão e para isso ele conta com o autor e por vezes com o editor, para impor explicitamente maneiras de ler, códigos de leitura. Esses códigos de leitura se apresentam das mais diversas formas e buscam identificar o leitor com a leitura fazendo com que esse ascenda àquela. Eles vão desde a estruturação da publicação (em forma de volume ou folhetim, por exemplo), passando por formas de orientar a leitura dos textos (prefácios, prólogos e epílogos, notas de rodapé, autógrafos e dedicatórias) até estratégias ideológicas de inserção no meio literário. Anna Ribeiro soube se utilizar de todas elas.

Não obstante, a primeira romancista baiana ter, aparentemente, ouvido o conselho do seu padrinho literário, publicando em seguida $\mathrm{O}$ anjo do perdão, folhetim ambientado no cotidiano do Recôncavo baiano do Oitocentos, outra estratégia da escritora das sinhazinhas era de não definir seu "estilo literário" buscando com isso fugir às criticas a ela direcionadas e adotando ao mesmo tempo apenas aspectos das correntes literárias românticas e realistas conforme a necessidade do cumprimento de seus objetivos. Ao indicar "as suas patrícias" "conselhos" que suscitem a "moral" e os "bons costumes" a autora busca uma identificação com elas. $\mathrm{Na}$ dedicatória de Letícia, Anna Ribeiro oferece o livro a sua prima Maria Joana de Araújo Góes e no prólogo do mesmo romance:

Oferecendo-te e a teu esposo meu humilde trabalho dirijo-me em particular a ti. Não esperes encontrar nele grande mérito literário [...]. Acharás, porém princípios de sã moral, bons exemplos tirados de fatos, nem todos imaginários e sim colhidos na experiência e observação (BITTENCOURT, 1908, p. I).

Não me dirijo aos homens repletos de conhecimentos científicos e literários [...]. Falo a vós, minhas patrícias que, dotadas de inteligência e gosto não vos contentais com fúteis passatempos, e procurais a leitura amena e agradável diversão ao espírito, colhendo lições e preceitos [...]. Não tenho pretensões a criar uma escola, o que seria incrível ousadia em vista da posição que ocupo no mundo das letras. Também, intencionalmente, jamais me filiei à escola alguma, porque isso é contrário a minha índole e gosto (Idem, p. V e VI). 
A sua estratégia constituía-se numa opção para ocupar um mercado literário ainda não explorado pelos escritores baianos naquele período: o romance de formação para mulheres. Anna Ribeiro era uma mulher informada, que lia livros e revistas da Europa, Portugal e Brasil, e por isso tinha consciência das lacunas deixadas pelo mercado. A aparente despretensão em se "enquadrar" numa escola literária, como ela mesma afirmava, era uma opção de não invadir um mercado literário já definido e ocupado por escritores do gênero masculino, que como se sabe, dominavam o cenário público naquele momento. Nada mais perspicaz e prudente do que criar o seu próprio público, - a elite feminina - quando o público já estabelecido - homens da elite - por questões do discurso dominante já tem um cânon literário definido. É preciso lembrar que a referida autora é uma mulher da elite típica do século XIX e que em sua visão, à mulher competia o papel de ajudante do homem, cabendo ao último o "cetro" [controle] da sociedade. Não se pode, no entanto, pensar em suas ações e forma de pensar a partir dos valores contemporâneos. Ainda assim, mulheres como Anna Ribeiro conheciam bem o mundo paternalista e patriarcal em que viviam, e por vezes, tracejavam dentro dele para conseguir seus intentos, sem que para isso fossem ao encontro da ideologia dominante. No caso das mulheres da elite, é válido lembrar que elas não eram tão submissas quanto se pensava e que elas sabiam como conseguir seus objetivos utilizando para isso o próprio discurso do dominador. A estratégia "humilde" de Anna Ribeiro para consolidar-se no cenário literário baiano é uma evidência disso. Seus romances "despretensiosos" foram sucesso de crítica. Tratava-se de uma mulher astuta e perspicaz que conhecia o mundo em que se introduzia e sabia também como mover-se nele. Almanachio Diniz, um dos maiores escritores da Bahia no século XIX, referindo-se à romancista do Recôncavo baiano tece comentários esclarecedores para o tema em questão:

$\mathrm{Na}$ Bahia, nesta terra estagnada e moritusa, ainda há quem cultive a literatura sem escândalos, modestamente, mas com superioridade de vistas.

Esta neste caso D. Anna Ribeiro de Góis Bittencourt, autora de várias novelas publicadas em folhetins de jornais desta capital e do bem mencionado romance "Letícia" com que abro essa série de ponderações críticas.

Num meio como o nosso de intrujices vindas nos porões dos navios de norte as sul do país, um romance aparecido com o fruto da terra é um acontecimento. E a crítica por mais vigorosa que entenda de certo, aponta defeitos em um livro que não tem similar para termo de comparação. Qual o romance de escritora baiana para entrar em comparação com "Letícia"? Louvado seja, portanto, quem trabalha em tempos como estes os meus aplausos a desinteressada constância nas letras que tem acentuadamente recomendado a Ins a. D. Anna Bittencourt (DINIZ, Almachio. Comentários sobre o romance Letícia. Material manuscrito). 
A crítica de Diniz, não obstante ser uma referência a "pratas da casa", e à valorização os escritores locais em detrimento dos de fora, é também uma alusão crítica à literatura realista e naturalista, ou mesmo romântica e um manifesto em favor da literatura de fins moralistas, campo em que segundo ele Anna Ribeiro atuava muito bem. Sobre isso também se pronunciou Gilberto Freire, em Sobrados e Mucambos:

Bem dizia em 1885 Da. Anna Ribeiro de Góes Bittencourt, ilustre colaboradora baiana do Almanaque de lembranças luso-brasileiro, alarmada com as tendências românticas das novas gerações - principalmente com as meninas fugindo de casa com os namorados - que convinha aos pais evitar as más influências junto ás pobres mocinhas. O mau teatro. Os maus romances. As más literaturas. Os romances de José de Alencar, por exemplo, com "certas cenas um pouco desnudas" e certos "perfis de mulheres altivas e caprichosas [...] que podem seduzir a uma jovem inexperiente, levando-a a querer imitar esses tipos inconvenientes na vida real" (FREIRE, 2004, p. 249).

Ao mesmo tempo em que cumpria sua missão de preparar as senhorinhas de engenho para as mudanças processadas na Bahia no final do Oitocentos, Anna Ribeiro também explorava a demanda oriunda da falta desse tipo de produção deixado pelos escritores da Bahia naquele momento.

Outra estratégia de inserção de Anna Ribeiro no cenário literário baiano se percebe já na sua segunda publicação, quando utilizou outro artifício para alcançar seu público alvo: os folhetins, publicados nos rodapés de vários jornais da capital e do interior baiano. D. Anna provavelmente sabia que o mercado literário voltado para as mulheres era muito restrito, e por isso voltou-se para as publicações folhetinescas em jornais, a priori, voltados para os homens ${ }^{6}$. Para os editores desses jornais, a publicação de folhetins voltados ao público feminino seria mais uma estratégia para alcançar um maior número de leitores, incluindo as mulheres. Trata-se de uma articulação de interesses mercadológicos bem delimitados e voltados para o consumo. Esses moldes seguiam tendências do mercado editorial francês, que naquele período servia de modelo civilizacional para o Brasil, inclusive a Bahia. Ainda no inicio da carreira literária da autora Augusto Blake fez um alusivo comentário sobre a entrada de D. Anna no mercado literário:

[Anna Ribeiro] Deu-se desde jovem à literatura, não só de seu país como a francesa; cultiva a poesia, e achando um certo encanto na decifração de charadas e logogrifos, tem composto uma grande numero deles, e publicado alguns no Al-

6 A historiadora Adriana Reis relata que em função das mudanças de comportamento na elite baiana que ocorreu a partir da segunda metade do século XIX, as mulheres da elite passaram por um processo de socialização, sendo que para isso surgiu um mercado editorial que publicava sugestões de moda e comportamento em sociedade (Idem). 
manaque luso-brasileiro de 1880 a 1882, no Almanaque da Gazeta de Noticias da Bahia de 1883, [...]. O anjo do perdão: escreveu a pedido de Antonio Lopes Cardoso e acaba de ser-lhe entregue para ser publicado na gazeta de Noticias da Bahia, em folhetins, e depois talvez seja impresso em volume (BLAKE, 1883, p. 94).

$\mathrm{O}$ romance $\mathrm{O}$ anjo do perdão reúne ao mesmo tempo o toque regionalista a que fora orientada por Taunay e a sugestão editorial do representante do jornal, o senhor Antonio Lopes Cardoso, o que evidencia a concatenação do projeto literário de Anna Ribeiro com as possibilidades impostas pelo mercado literário, não só em relação aos romance mais facilmente "aceitáveis" pelo público, mas pelo meio de comunicação mais recomendado para alcançá-lo, nesse caso a publicação em forma de folhetim. Com isso, a autora consegue alcançar suas leitoras, sem comprometer a essência de sua mensagem: o ideal de comportamento e de ação da mulher para manutenção ou mesmo adaptação do seu grupo social frente às mudanças que a Bahia vivia no final do século XIX. Alguns anos depois a tática da autora foi se utilizar de meios de comunicação especializados assumidamente voltados para um público feminino, tais como as revistas $A$ Voz e a Paladino do Lar, ambas as publicações da Liga Baiana das Senhoras Católicas.

A última estratégia utilizada pela romancista baiana foi o tom realista das tramas dos seus romances. Certamente as leituras dos romances europeus do século XVIII a influenciaram muito nisso. Ribeiro lia freqüentemente esses romances desde a sua mocidade quando um monge amigo da família lhe emprestava. Os formatos dos romances que ela seguia em seus escritos corroboram a visão enunciada pelo critico literário Ian Watt, tanto na "reconstituição" do ambiente vivido quanto na busca da individualização e identificação das personagens ${ }^{7}$. Seu intuito era buscar uma identificação da leitora com a leitura, garantindo-lhe, ao mesmo tempo, o cumprimento da função de "testemunho histórico" dos seus romances. O cruzamento das histórias contadas em seus folhetins com as memórias por ela escrita esclarece bem essa opção. Muitos sujeitos históricos que ela menciona em seu livro de memórias são nitidamente recriados nos enredos romanescos. É este o caso de seu pai Mathias de Araújo Góes e sua correlação com o senhor Travassos, pai da protagonista de Letícia, para citar um dos inúmeros exemplos. O comportamento, a personalidade o tratamento com os escravos são idênticos, até a morte dos dois são parecidas: enquanto o pai de Anna Ribeiro morreu doente por se

7 Ian Watt faz um estudo sobre os romances ingleses no século XVIII, utilizando como estudos de casos os escritores Defoe, Richardson e Fielding. Nesse estudo, esse teórico da literatura, faz um apanhado sobre o romance enquanto gênero literário na Europa naquele período, em seus perfis e caracterizações básicas (WATT, Ian. A ascensão do romance: estudos sobre Defoe, Richardison e Fielding. São Paulo: Cia. das Letras, 1990). 
negar a ir fazer tratamento na capital, o pai da personagem toma a mesma decisão. Sujeito histórico e personagem se queixavam não terem sido devidamente ressarcidos pelos cativos libertados em maio de 1888, expressando assim o sentimento da elite baiana frente à posição do governo imperial. $\mathrm{O}$ tom realista de Anna Ribeiro em seus textos romanescos são um oportuno ponto de partida para entender as representações de elite sobre a experiência do final do Oitocentos. Sobre a forma realista expressa Ribeiro certa vez:

O romance não é mais uma fantasia de imaginação para o divertimento das damas, porém sim uma obra séria, cujos detalhes são documentados e na qual os investigadores do século próximo irão encontrar escrita, dia a dia a história do nosso século (BIT"TENCOURT, 1916, p. 91).

Observa-se que, para a autora, o romance teria que oferecer uma leitura com a qual seus apreciadores poderiam se identificar. Ele necessitaria ter também funções bem definidas, deveria focalizar a vida como ela era ou pelo menos como os autores a representavam. Deveria também mostrar a realidade e os problemas que essa apresentava, e deveria conter noções e posturas para superar as dificuldades que a classe senhorial enfrentava na Bahia dos fins do século XIX. Uma análise da produção dessa autora oferece uma fácil identificação de como ela se utilizava do realismo, no que tange à representação da realidade. Isso fica claro na composição do ambiente de suas tramas, pois suas histórias sempre se passam no Recôncavo Baiano. Seus romances registram por vezes acontecimentos históricos presenciados pela autora e a mais importante de tudo suas personagens são inspiração em sujeitos históricos que conviveram com ela. Pesavento reitera que tanto a história quanto a literatura são formas de explicar o presente, inventar o passado e imaginar o futuro. Ela também afirma que se a intenção for utilizar tais textos nos moldes "oficiais" a literatura não terá muito a contribuir. Se por outro lado a intenção do historiador for o resgate das representações passadas, as significações e formas de enxergar o mundo em um dado período, a literatura é uma das fontes privilegiadas ${ }^{8}$. Por certo a função da escritora baiana não era remeter as representações de seu tempo e sim documentá-las da forma mais positivista, segundo as leituras que fazia na Faculdade de Medicina da Bahia, porém isso só fez enriquecer sua literatura enquanto fonte para os historiadores do nosso tempo, os chamados historiadores da cultura.

A atuação de Anna Ribeiro no cenário literário dominante não foi passiva, nem débil. Muito pelo contrário, ela soube transitar dentro das limitações impostas pelo cânon dominante e soube também se aproveitar da sua posição social para conseguir construir sua trajetória literária. Outras mulheres também se aventuram

8 PESAVENTO, Sandra Jathay. História e história cultural. Belo Horizonte: Autêntica, 2004. 180 A Cor das Letras - UEFS, n. 8, 2007 
diante do difícil, mas não impossível desafio de transitar num mundo dominado pelos homens, como a escritora Amélia Rodrigues, a quem Anna Ribeiro considerava como uma de suas mestras. Essas e outras mulheres formaram nesse período o que a historiadora Márcia Barreiros chamou de "rede de solidariedades femininas" em sua tese de doutorado em História Entre a tinta e o papel: memórias de leituras e escritas femininas na Bahia (1870-1920), publicado em forma de livro pela editora Quarteto em 2004. Essa "rede de solidariedades" ajudou a compor uma "frente de batalha" contra as "inovações vindas de fora" e a "depravação moral da sociedade". Na década de 1910, esse mesmo grupo publicaria as primeiras revistas femininas publicadas e editadas predominantemente por mulheres $A$ Voz e $A$ Paladina do Lar.

As críticas e os comentários dos principais autores baianos da época sobre autoras como Anna Ribeiro, dão a impressão de que as mulheres que se inseriram no mundo das letras naquele período, seguindo os parâmetros do mercado literário hegemônico, tiveram bons resultados e não foram "silenciadas" como sugere Nancy Vieira Fontes em sua dissertação sobre Anna Ribeiro. Nancy Fontes sugere que a autora oitocentista teria sido "esquecida" da literatura baiana por ser a primeira mulher a escrever em prosa naquele estado, sofrendo assim com o preconceito em mundo dominado pelos homens e que as autoras femininas teriam sido "silenciadas" pelo cânon dominante eminentemente preconceituoso e machista.

Um olhar atento sobre a trajetória de escritoras como Anna Ribeiro mostra que ela esteve no cenário literário por várias décadas, publicando em vários meios de comunicação, inclusive livros encadernados em editoras de Salvador. Se ela foi "silenciada" como conseguiu produzir por tanto tempo? Como conseguiu publicar tantos trabalhos? Como já foi apontado anteriormente, pelo menos durante o período de sua atuação no cenário literário ela se manteve dentro do mercado literário, em seguimento que não comprometia o mercado hegemônico, e talvez por isso pode se desenvolver. Anna Ribeiro soube atuar esse mercado, tinha consciência do domínio masculino naquele mundo e não o negava, mas sabia como transitar nele, conseguindo aquilo que julgava necessário para cumprir sua "missão literária".

\section{REFERÊNCIAS}

ALVES, Marieta. Intelectuais e escritores baianos: breves biografias. Salvador: Prefeitura Municipal do Salvador: Fundação do Museu da Cidade, 1997.

BITTENCOURT, Anna Ribeiro de Góes. Longos serões do campo: infância e juventude. Organização e notas Maria Clara Mariani. Rio Janeiro: Nova Fronteira, 1992, 2 vol.

BITTENCOURT, Anna Ribeiro de Góes. Letícia. Salvador: Litho-Typ. e Encadernação Reis \& Cia., 1908.

BITTENCOURT, Anna Ribeiro de Góes. Anna Ribeiro de Araújo Góes. Exaltação. $A$ Voz da Liga Baiana das Senhoras Católicas. Salvador, n. 6 set. 1916. 
BLAKE, Augusto Alves Victorino Sacramento. Dicionário bibliográfico brasileiro. Rio de Janeiro: Tipografia Nacional, 1883.

BOURDIEU, Pierre; CHARTIER, Roger. A leitura: uma prática cultural. In: CHARTIER, Roger. (Org.). Práticas da leitura. São Paulo: Estação Liberdade, 2001.

BURKE, Peter. Variedades de história cultural. Rio de Janeiro: Civilização Brasileira, 2000.

CHALHOUB, Samira. Machado de Assis historiador. São Paulo: Cia. das Letras, 2003.

CHARTIER. Roger. A história cultural: Entre práticas e representações. Lisboa, Deferiu, 1990.

CHARTIER. Roger. A ordem dos livros. Trad. Mary Del Fiori. Brasília: Universidade de Brasília, 1994.

DINIZ, Almachio. Comentários sobre o romance Letícia. Material manuscrito. [S.d.].

FREIRE, Gilberto. Sobrados e mucambos: decadência do patriarcado e desenvolvimento do urbano. 15. ed. ver. São Paulo: Global, 2004.

FONTES, Nancy Rita Vieira. A bela esquecida das letras baianas: a obra de Anna Ribeiro. Orientador: Profa. Dra. Ívia Iracema Duarte Alves. Salvador, 1995. Mestrado em Letras/UFBA, 1999.

FIGUEIREDO, Eurídice, NORONHA, Jovita. Identidade nacional e identidade cultural. In: FIGUEIREDO, Eurídice. (Org.). Conceitos de identidade e cultura. Juiz de Fora: UFJF, 2005.

MATTOSO, Kátia M. de Queirós. Babia século XIX: Uma Provincia no império. 2. ed. Nova Fronteira: Rio de Janeiro, 1992.

PESAVENTO, Sandra Jatahay. História e história cultural. Belo Horizonte: Autêntica, 2004.

POLLAK, Michael. Memória e identidade social. Estudos Históricos, Teoria e História. Rio de Janeiro, FGV, n. 10, 1992.

REIS, Adriana Dantas. Cora: lições de comportamento feminino na Babia do século XIX. Salvador: Centro de Estudos Baianos da UFBA, 2000.

WATT, Ian. A ascensão do romance: estudos sobre Defoe, Richardison e Fielding. São Paulo. Cia. das Letras, 1990. 